\title{
Team-Based Interaction in the Foodservice Instructional Laboratory: An Exploratory Model of Team Composition, Team-Member Interaction, and Performance
}

\author{
Alex M. Susskind \\ Cornell University \\ Carl P. Borchgrevink \\ Michigan State University
}

Final version published in Journal of Hospitality \& Tourism Education, 10:4, 22-29

Alex M . Susskind* is an assistant professor in the School of Hotel Administration at Cornell University.

Carl P. Borchgrevink is the program director of the School of Hospitality Business at Michigan State University.

*Correspondence concerning this manuscript should be directed to Alex M. Susskind. 
Much like the "hard sciences," hospitality laboratory-based education is a frequently required component of academic programs due to the applied nature of the concepts taught. Laboratory courses in hospitality education are typically designed around foodservice based activities, such as operating a restaurant or components there of; lodging-based activities, such as running a front desk or housekeeping department; or gaming-based activities, such as running games and entertainment processes in a casino. While the activities mentioned above may not be present in all hospitality programs, it safe to say that the majority of well-rounded hospitality education programs offer some form of laboratory instruction consistent with their educational mission and specialty. In this investigation foodservice laboratories will be used as a frame of reference and focal point to examine team interaction. It is likely that these concepts could be applied equally well in a number of laboratory settings both in and outside hospitality education.

\section{The Foodservice Laboratory}

Due to the applied nature of hospitality management and the prevalence of foodservice management in the hospitality industry, hospitality education curricula typically contain a variety of foodservice laboratory-based classes. The setup and structure of these courses can range from a basic food preparation course taught in a teaching kitchen to an upper-division "operations" course in which the students plan, operate, and evaluate a functioning foodservice operation. In the former case. The students are typically exposed to quantity food production principles designed to lead to advanced applications. In the latter case, the students are typically responsible for running a foodservice operation (e.g. restaurant, cafeteria, or catering banquet facility) that is usually open to the public. Both of these types of classes are present in culinary schools, 
associate degree programs, and bachelor degree programs with the goal of providing hospitality students with practical foodservice experience in a controlled learning environment.

\section{Teamwork in Laboratory Education}

Due to the structure and nature of laboratory activities, laboratory classes typically divide students into teams or groups to complete laboratory assignments. Teams are used in the laboratory to facilitate equitable exposure to all of the laboratory-based experiences. In essence, teams allow each of the students to rotate through the class activities to maximize equipment and facility utilization, and streamline instruction and the production of class activities. For example, a one- week breakout of teams in a student-run restaurant could consist of two or three teams assigned to table service duties in the "front-of-the-house" while the remaining teams are assigned to culinary production. sanitation and support activities.

In the following week the rotation would shift teams into different positions, with the objective of having each student team rotate through each position an equal number of times. In essence, team interaction and activities among student teams are designed to lead to enhanced learning through the formal and informal exchange of knowledge (Deeter Schmelz \& Ramesy. 1998,) based on the assumption that the sum of individual actions is not greater than the collective team effort (von Bertalanffy, 1968).

\section{Teams Defined}

A team is a collection of two or more individuals who are assembled for a common purpose share a temporal existence (past, present. Or future,) and interact with one another yet remain independent in some form or another (ligen, Major. Hollenbeck, and Sego. 1993). In 
work settings, a well-focused team effort is often associated with more effective outcomes through an interactive enrichment of work and social processes (Campion, Medsker and Higgs, 1993; Campion, Papper and Medsker, 1996; Hackman, 1987.) However, teams that are mismatched, maladjusted, or unfocused may experience abnormally high levels of conflict which is negatively associated with team member satisfaction and cohesion (Jehn, 1997). While a certain level of conflict is desirable in team interaction, excessive amounts of conflict often disrupt task-related duties (Jehn, 1997). The investigation into team interaction and its influence on individuals in organizations is of great practical significance to educators who use team-based instruction, and represents an extension of research conducted on work-based teams and teambased systems in organizational settings (Campion et al., 1996.)

Given the time and project specific Nature of laboratory activities, teams formed around laboratory activities in the foodservice laboratory can be characterized as project teams (or groups.) A project team is defined as a collection of individuals assembled for a time-specific single function that requires a blend of special skills and abilities (Cohen and Bailey. 1997.) As such, the team setting facilitates interactive projects and allows team participants to be exposed to a variety of experiences that uniquely contribute to learning. Team-based interaction is relevant to aspiring managers who will be ultimately charged with the duty of supervising and directing organizational work groups and processes (Freeman, 1996.) This is particularly relevant given that foodservice laboratory settings are close facsimiles of true-to-Iife operations.

A number of recent investigations have identified elements of the team process and how team interaction is related to performance in classroom settings, addressing issues such as individual ability, team size, and team composition (Deeter-Smelz \& Ramsey, 1998; Bacon, Stewart, Stewart-Belle. 1998). These investigations do not, however, address laboratory 
instruction, where team interaction is more closely and immediately related to output and performance processes. Likewise, in the organizational behavior and communication literatures, characteristics such as team size and composition (Bettenhausen, 1991; Campion, et al., 1993; Cohen \& Bailey, 1997,) team-member exchange (TMX) (Seers, 1989, Seers, Petty \& Cashman, 1995,) team member satisfaction and cohesion (Stokes, 1983; Seers, 1989,) team performance and effectiveness (Campion, et aI., 1993; Campion, et aI., 1996;Guzzo and Shea, 1992; Sundstrom, Demeuse and Futrell, 1990,) and team productivity (Pritchard. 1992;Pritchard. Jones, Roth, Stuebing, and Eekeberg, 1988; Shiflett. 1979) have received considerable research attention.

Despite the volume of research available, much of the team-based research is limited by generality as it is implemented using contrived teams (exception noted for Campion and colleagues, 1993; 1996.)In these instances, the teams are primarily assembled to test propositions and hypotheses rather than to specifically accomplish normal. Salient job-related tasks or objectives. As such, it is likely that the participants of the "contrived" teams place limited significance on the goals, outcomes, or rewards of the activities. In addition, team members are often randomly assigned to their teams and cannot discern or identify the specific purpose for being assigned to the team. Conversely, interaction in the advanced-level foodservice laboratory provides the students with tangible, identifiable tasks and assignments which are easily identified by the participants is based on clearly articulated and standardized course objectives and is designed in such a fashion that tasks are completed by intact project teams assembled specifically to meet measurable objectives during the length of a semester. Additionally, in an advanced food service laboratory, students not only receive feedback from the instructional 
support staff and peers but also receive direct feedback from the consumers of the laboratory efforts and products, mirroring a true food service encounter.

Given the void in team research using examining intact teams, the goal of this article is to introduce and test a model of team processes and outcomes in a controlled quasi-field setting in which the teams were assembled for a specified reason other than to conduct research. In essence, the use of naturally occurring work teams provides for additional empirical tests of theoretical propositions currently present in the team-based literature (Campion, et al., 1993; 1996.)

\section{A Model of Team Interaction and Research Hypotheses}

The model presented in Figure 1 displays team interaction in terms of team members' reactions to the team process, examining the influence of their perceptions and attitudes in regard to team performance. The model begins with team characteristics hypothesized to exert a positive influence on TMX. Team-member exchange is presented as a positive influence upon cohesion. Cohesion is presented as a positive influence on both team-member satisfaction and team performance. Each relationship is described below.

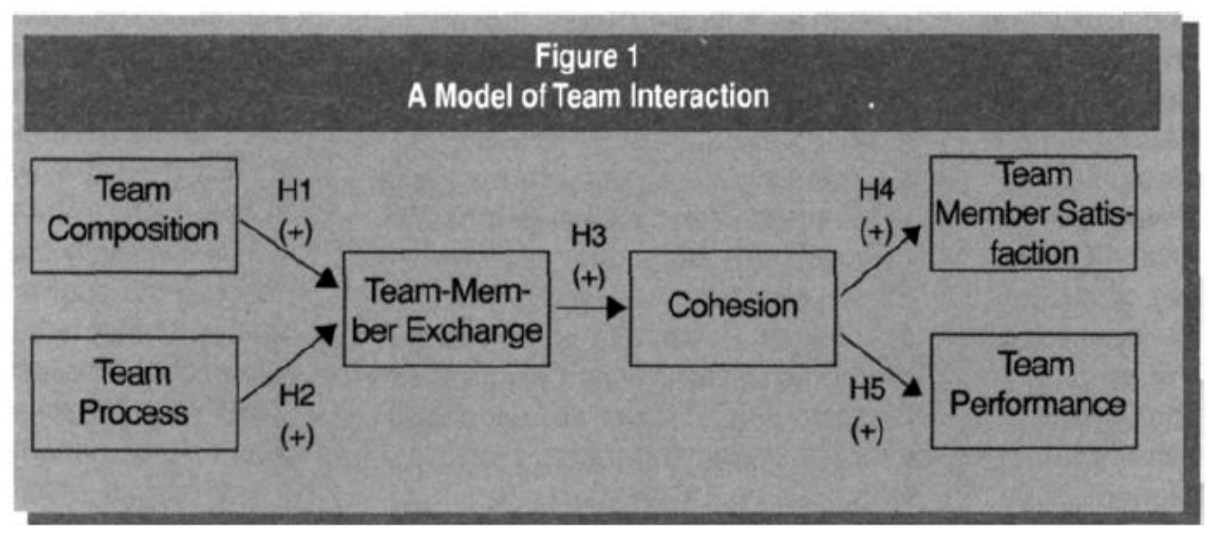




\section{Team Characteristics}

Specific team-based characteristics and their relationship to team based outcomes have been well identified in the literature (Campion, et aI., 1993; Magjuka and Baldwin, 1991). Team characteristics and their relationship to jobs and tasks are likely to have a varied influence among teams. In the specific case of specialized teams such as project teams, composition and process are identified as important influences of team interaction.

\section{Composition}

Team composition is reflected in a number of reviews which relate effectiveness to composition (Campion, et aI., 1993; 1996; Cohen and Bailey, 1997; Hackman, 1987; Sundstrom, et al., 1990.) Composition can be examined in terms of member demographics and experience (Cohen and Bailey, 1997; Sanders \& Carpenter, 1998,) member preference for team interaction (Guzzo \&Shea, 1992), and objective team qualities such as size or location (Campion, et aI., 1993; Cohen \& Bailey, 1997; Sanders \& Carpenter, 1998; Sundstrom, et al., 1990.) Specifically, in terms of maintaining an effective team, Campion et al. (1993) suggest: (a) team member skills and abilities be well blended (heterogeneity), (b) team members be capable of assisting each other in terms of task performance and execution (flexibility), (c) team size is sufficiently large to complete the task, yet not too large as to inhibit effective performance (relative size), and (d) that individuals who prefer team work and team interaction are likely to be more effective in their efforts (preference for group work.) Each of the composition factors mentioned above describe the basic underlying characteristics of team membership and are presented as a joint influence upon team interaction along with process based characteristics. A well-composed work 
team is anticipated to lead to higher levels of TMX as the team should be appropriately balanced in membership and abilities to perform team tasks effectively (Hypothesis 1.)

\section{Process}

Process refers to team activities that influence team outcomes (Campion et aI., 1993.) For example, when team members believe their team is effective in its efforts (potency,) that individual team contributions are justly and easily identified (workload sharing,) and information flow occurs among team members (communication within work teams,) it is likely that the team will be more effective (Campion et aI., 1993.) Therefore, team members indicating positive team process influences are anticipated to report higher levels of TMX (Hypothesis 2.)

\section{TMX}

Team member exchange is a construct which considers team members' perceptions of individuals' willingness or desire to help other team members, and to provide and receive feedback, help, support, or information from team members (Seers, 1989). Team-member exchange is related to, but separate from, perceptual and attitudinal variables such as cohesiveness and team member satisfaction, because TMX examines an individual's perception of their role in the team process rather than their perception of a team as a whole (Seers, 1989; Seers, Petty, \& Cashman, 1995.) Team-member exchange is typically conceptualized from two distinct yet interrelated perspectives - exchange of information and exchange of effort (Seers, 1989.)As a relatively new construct in team research, TMX assesses the extent to which team members personally perceive a sense of 'leamness" in terms of task-based interaction (Bettenhausen, 1991; Seers, Petty, \& Cashman, 1995.) 


\section{Team Cohesion}

At the individual level, cohesion is often defined as positive feelings toward team membership or the sharing of similar attitudes among team members (Danowski, 1980; Shah, 1998; Stokes, 1983.) Cohesion is typically a result of perceived interpersonal closeness among team members and is an essential part of team interaction (Betten hausen, 1991.) Cohesion has been extensively used as an outcome variable in team-based research (Pavitt \& Curtis, 1990) and has been linked to performance-based outcomes (Seers, et aI., 1995) and team member satisfaction (Pavitt\& Curtis, 1990.) High levels of perceived team interaction in terms of TMX are anticipated to positively influence cohesion (Hypothesis 3.)

\section{Team Member Satisfaction}

Team member satisfaction is typically described as a maintenance variable in team interaction and is an often treated as an outcome variable in team research (Pavitt \& Curtis, 1990; Sundstrom, et aI., 1990.)Team member satisfaction is strictly perceptual in nature (Seers, 1989, ,) and is directly influenced by members' assessment of team interaction in terms of cohesion (Pavitt \& Curtis, 1990.)

\section{Team Performance}

How a team performs is a function of several factors. First the team must be capable of performing the duties or tasks assigned to them, meaning their membership is competent and can be effective. Secondly, the team must be motivated to perform the duties or tasks with which they are charged, and the team must have the structure of support needed to effectively complete their tasks (Deeter, Schmelz \& Ramsey, 1998; Pavitt \& Curtis, 1990.) While a team's output can 
be normally characterized as a collection of coordinated efforts, each team member has the potential to influence the collective team output (positively, negatively, or innocuously.) Team performance can be identified as the degree to which a team's output meets specified performance or outcome objectives and is likely to be highly influenced by team cohesion. In Figure 1, cohesion is modeled to exert a joint, positive influence upon team member satisfaction (Hypothesis 4) and team performance (Hypothesis 5.)

\section{Methods}

\section{Participants}

Thirty-seven hospitality management students enrolled in an "advanced foodservice management" laboratory course at a large southeastern university were surveyed for this investigation $(\mathrm{N}=37$.) By gender, the participants were $62 \%$ male and $38 \%$ female, all between the ages of 20 and $27(\mathrm{M}=21.75$.$) The professor divided the participants into nine teams based on$ their qualifications and food service relevant experience based on the students' responses to an "experience profile." Teams were balanced so experienced and non-experienced individuals comprised each team. Eight of the teams were comprised of four members and one team was comprised of five.

\section{Measurement}

\section{Survey Measures}

Survey measures evaluated variable subjects' perceptions of team characteristics, TMX, group cohesiveness, and group member satisfaction in a cross sectional design. Participants were asked to indicate their level of agreement with each scale item on a five-choice metric (strongly 
agree, agree, neutral, disagree, and strongly disagree.) Variable negatively worded items were reverse coded to maintain consistency with the direction of each scale.

\section{Team Characteristics}

A total of 24 items were adapted from them composition and process themes presented in Campion et al. (1993). Work Group Characteristics Measure to assess relevant team characteristics. Two of the four dimensions of the composition theme were included: (a) heterogeneity ( 3 items) and (b) preference for team work (three items). Three of the four process dimensions were included: (a) potency ( 3 items), (b) workload sharing ( 3 items), and (c) communication within work teams ( 3 items.) It should be noted that Campion et al, (1993) identified a total of 19 themes measured by 54 items to assess work group effectiveness. As mentioned in Endnote 1, the dimensions of context, job design, and inter dependence were not included, as these constructs were not directly applicable to the project teams under investigation. Furthermore, not all of the themes presented in the composition and process dimensions were applicable among these project team participants, given that the team structure, team process, and project parameters were dictated and controlled. The reliability coefficients (Cronbach's Alpha) for the composition and process domains were $\alpha=.71$ and $\alpha=.92$, respectively. 


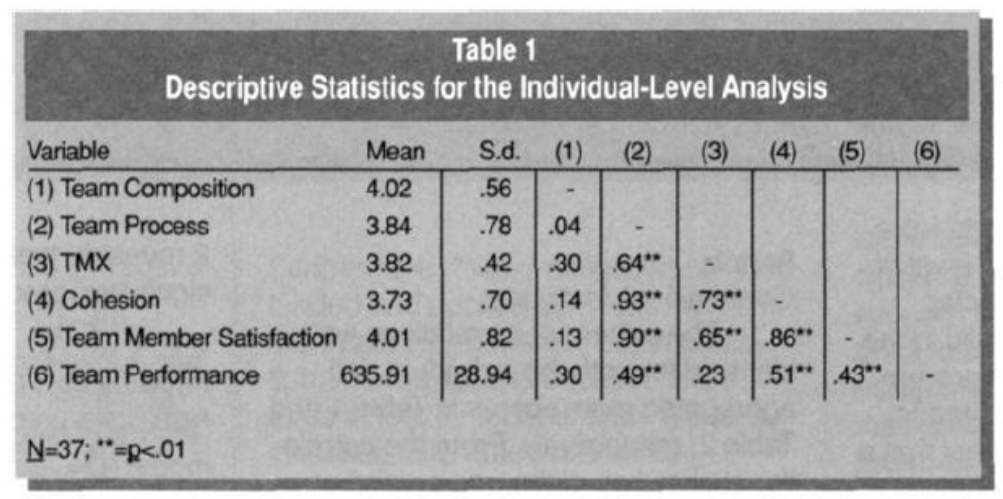

\begin{tabular}{|c|c|c|c|c|c|c|c|c|}
\hline \multicolumn{9}{|c|}{$\begin{array}{c}\text { Table } 2 \\
\text { Descriptive Statistics for the Team-Level Analysis }\end{array}$} \\
\hline Variable & Mean & S.d. & (1) & (2) & (3) & (4) & (5) & (6) \\
\hline (1) Team Composition & 4.02 & 28 & $\cdot$ & & & & & \\
\hline (2) Team Process & 3.84 & .72 & .01 & - & & & & \\
\hline (3) $T M X$ & 3.82 & 42 & .02 & $.78^{*}$ & - & & & \\
\hline (4) Cohesion & 3.73 & .70 & .06 & $.99^{* *}$ & $81^{\circ}$ & - & & \\
\hline (5) Team Member Satisfaction & 4.01 & 82 & .00 & $.98^{* *}$ & $87^{*}$ & $.97^{* *}$ & - & \\
\hline (6) Team Performance & 635.00 & 29.99 & 54 & .56 & .39 & 60 & 52 & - \\
\hline$N=9 ; "=\mathbb{R}<.05 ; " *=\mathbb{R}<01$ & & & & & & & & \\
\hline
\end{tabular}

\section{TMX}

Team-member exchange was measured from the two perspectives presented by Seers (1989.) Exchange of information and exchange of effort were both measured using six-item scales. The reliability coefficient for the TMX scale including both dimensions was $\alpha=.76$.

\section{Cohesion}

Attitudinal cohesion was measured using a six-item scale adapted from Stokes (1983.) Attitudinal cohesion measured team members' perceptions of "closeness" among other team members. The reliability coefficient for the cohesion scale was $\alpha=.84$. 


\section{Team Member Satisfaction}

Team member satisfaction was assessed with a three item measure adapted from Stokes (1983.) As measured, team member (5) (6) satisfaction provides an effective description of each participant's contentment with his or her team and its adequacy. The reliability coefficient for the team satisfaction scale was $\alpha=.81$.

\section{Team Performance}

Each team's performance was assessed at various intervals during the semester, as project components were completed and turned in for evaluation and grading. Each team was rated on an aggregated 700-pointscale, by the professor who included ratings of each team's planning efforts, operational efforts, such as management and training, financial aspects, implementation efforts, and post-function evaluations. Each team's output was evaluated using a standardized rating form to evaluate the noted criteria consistently across the nine groups. Although each team member was also evaluated individually in a variety of ways, these scores were not included to protect the anonymity of the participants.

\section{Analyses}

Due to size of the sample $(\mathrm{N}=37, \mathrm{~K}=9)$ and the number of questionnaire items presented (36,) neither confirmatory nor exploratory factor analyses were applied to the data due to extremely low respondent-to-item ratio. In this case the respondent-to item ratio was approximately one. A conservative estimate present in the literature suggests that at least ten subjects be used per item (Hinkin, Tracey, \& Enz, 1997.) In this investigation, only previously validated instruments were used which can provide some level of confidence that the items 
selected were content and construct valid in the research domains in which they were created and validated. By no means, however, do the authors suggest that a construct validation process should be excluded from use if previously validated items are selected. Given the exploratory nature of this study, it would be useful, in a preliminary sense, to examine patterns of relationships among the variables and how they describe team members' perceptions and performance. The inter-item correlations of the scales are reported in Table 1 for the individual responses $(\mathrm{N}=37)$ and the combined teams $(\mathrm{k}=9)$ are presented in Table2.

\section{Path Analyses}

The model presented in Figure 1 was tested two ways using least squares static path analysis with PATHE (Hunter \& Hamilton, 1995) to assess the variables' interrelationships and general predictive character. The first test utilized the individual responses $\mathrm{N}=37$,) and the second test used the aggregated responses by team $(\mathrm{k}=9$.)

Path models were assessed for fit based on the recommendations that global chi-square tests for the sum of squared error for the model be nonsignificant, and each link in the model be tested for significance by calculating a confidence interval around the observed correlations.

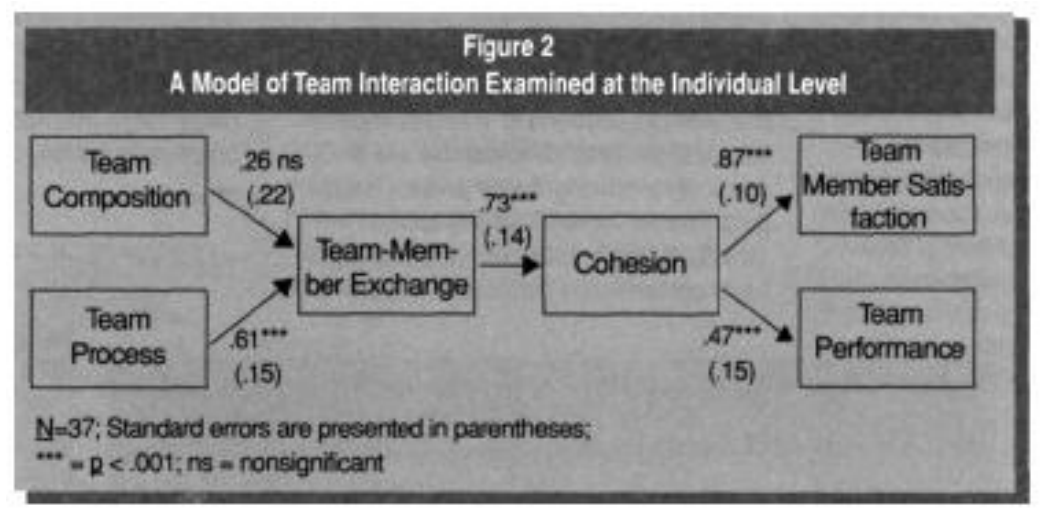




\section{Results}

\section{Correlational Analyses}

The pattern of correlations was identical for both the individual and aggregated team scores in Table 1 and Table2, respectively. From the correlational analyses of the aggregated scores, it is evident that the process, TMX, and cohesion variables are strongly related to both team member satisfaction and moderately related to performance. Only team composition demonstrated weak relationships in regard to the other variables measured through the participants' self-reports. However, performance (measured independently) demonstrated a consistent relationship to all of the attitudinal and perceptual measures, with correlations ranging from a low of .39 for TMX to a high of .60 for cohesion. This suggests that the variables measured here are relevant to the assessment of team processes and interaction from both the individual and team levels.

\section{Path Analyses}

\section{Individual-Level Analyses}

The model presented in Figure 2 demonstrated a very good fit to the data $\left(\mathrm{X}^{\wedge} 2[9]=10.45\right.$, $\mathrm{Q}=.315$ ) using the responses from the 37 participants without considering their team affiliation. The test of Hypothesis1 yielded the only nonsignificant path coefficient in the model from team composition to $\operatorname{TMX}(\beta=.26$, ) indicating that these respondents did not view the composition of their team as an important influence upon the exchange of information and effort within their group. This most likely occurred because the teams were selected and formed by a force external to the group (Le., the professor.) The test of Hypothesis 2 revealed that team process was a significant predictor of TMX in the model $(\mathrm{N}=.61, \mathrm{Q}<.001$. $)$ The test of Hypothesis 3 revealed 
that TMX was a significant predictor of cohesion in the model $(\mathrm{N}=.73, \mathrm{Q}<.001$,$) and cohesion$ significantly influenced both team satisfaction $(\sim=.87, \mathrm{Q}<.001)$ and performance $(\mathrm{N}=.47, \mathrm{Q}<$ $.001)$ in the tests of Hypothesis4 and Hypothesis 5, respectively. As indicated by the correlational analyses and confirmed by sampling error analyses, the "process" variable indicated significant relationships to both cohesion and team satisfaction. While these "non-specified" relationships proved to be significant, the test of Figure 2 falls well within the expected confidence intervals, suggesting that the model, as presented, is well suited to the data.

\section{Team-Level Analyses}

The model presented as Figure 3 also demonstrated a very good fit to the data (X $2(9)=10.45,12=.315)$ using the responses from the 37 participants aggregated by their team assignments into their nine teams. As in Figure 2, the test of Hypothesis 1 yielded the only nonsignificant path coefficient in the model from team composition to TMX $(\mathrm{N}=.03)$, indicating once again that the teams did not view composition elements as an important influence upon the exchange of information and effort within their group. The test of Hypothesis 2 revealed that team process was a significant predictor of TMX in the model $(\mathrm{N}=.78,12<.001$.) The test of Hypothesis 3 revealed that TMX was a significant predictor of cohesion in the model $(\beta=.81$, $12<\cdot 001$,$) and cohesion significantly influenced team satisfaction (\mathrm{N}=.97$. $\mathrm{g}<.001)$ and performance $(\mathrm{N}=.60, \mathrm{~g}<.01)$ in the tests of Hypothesis 4 and Hypothesis 5 , respectively. Again, as indicated by the correlational analyses and confirmed by sampling error analyses, the process variable demonstrated significant relationships to both cohesion and team satisfaction. While these "non-specified" relationships were significant. The test of Figure 3 as presented falls well within the expected confidence intervals, suggesting that the team-level 


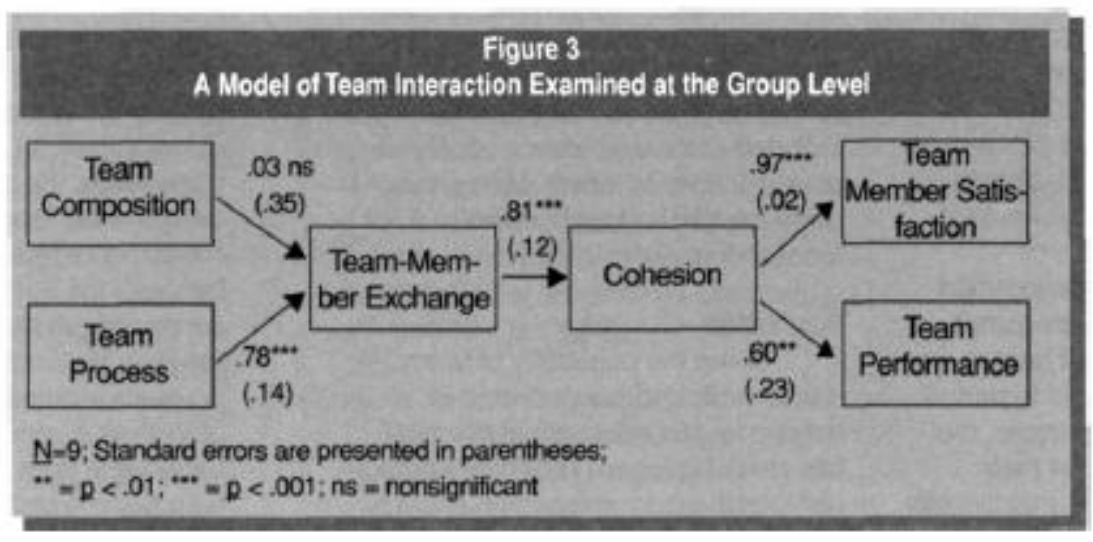

model fit the data. Given the nature of the data, one would expect the individual responses to mirror those of the aggregated team responses, as one is a function of the other. This is confirmed not only through the path analyses, but also through the descriptive statistics and correlational analyses. While the means remained the same (within rounding error,) the standard deviations differed as the difference in sample size (e.g. 37 versus nine) led to a lower variance in a strict mathematical sense.

\section{Discussion}

The examination of team processes in action continues to be of interest to a variety of constituents both in and outside the academy. This investigation examined team-based processes and outcomes in quasi-field settings using intact work groups in an instructional foodservice laboratory. Furthermore, this investigation extended and applied concepts from the organizational behavior, communication, marketing, and education literatures to test a model of team process, influence, and out comes in the foodservice instructional laboratory. Both individual and aggregate team scores led to the same conclusions and suggest that both perspectives are appropriate to examine team interaction. The level of measurement and analysis should be carefully considered and match the data under investigation. In this case, the team 
characteristics, process, and outcome variables appear best suited to team level interpretation, despite a relatively small sample of teams.

Four notable findings emerged from this investigation. First, reports of team process proved to be highly related to TMX in the path models and strongly related to cohesion and team member satisfaction in the correlational analyses. This suggests that team members' affective evaluation of team interaction led not only to perceptions of "team ness" as measured by TMX but also indirectly influenced their sense of cohesion and satisfaction with their team. It should be noted that the process variable demonstrated notably stronger relationships among the affective variables (Le, TMX, cohesion, and team member satisfaction) compared to the objective outcome variable (performance.)

Second, TMX, as applied here and presented in previous research (Seers, 1995; Seers, et aI., 1995,) demonstrated strong relationships among the cohesion and satisfaction variables. In essence, if team members perceived an equitable exchange of information and effort among their team, they were more likely to report closer relationships and more satisfaction with their team members. This has great implications for team-based assignments in laboratory or classroom settings. Teams should be assembled in a fashion that maximizes the potential for individual contribution to the team process and facilitate the exchange of effort and information. Unfortunately, many instructors implementing groups for assignments assign individuals randomly or with little consideration for individual differences. In fact, most instructors have previous exposure to the students in other settings or colleagues with such exposure, which can provide insight to aid in the formation of project teams. For example, a particularly quite or softspoken individual may not fare well among a group of outspoken individuals; certain cultural norms pertaining to interaction may also inhibit such equitable exchange. These findings 
highlight the need to design teams so that learning can be transferred through team interaction and exchange in addition to instructional support or activities.

Third, reports of team cohesion proved to be a strong indicator of team member satisfaction and performance, suggesting that cohesive teams were more likely to be satisfied with their team and demonstrate better performance. These relationships are consistent with findings in the group literature (Pavitt \& Curtis, 1990,) and should be carefully considered when using teams. Activities such as team building may help develop a team's level of cohesion that will likely lead to higher levels of satisfaction and performance, connected to the transfer of learning. Future research should continue to examine the influence of cohesion in team settings.

Lastly, while team composition proved to be an insignificant component in the model overall, it demonstrated a strong relationship to performance $(r=.54$.) With this sample, the respondents did not choose their teams and each team was intentionally well diversified to ensure a blend of member skill and ability to complete laboratory activities. As such, the respondents most likely did not view composition as an effective response but rather as a constant. The noted relationship between team composition and performance indicates that a well composed team is more capable to perform but suggests cognitive evaluations of the team process occur through other means.

\section{Limitations}

In this exploratory pilot study, a relatively small sample was used. While this in and of itself is not a reason to invalidate the findings presented herein, it presents a few methodological concerns that should be identified. First, factor analyses could not be effectively used due to sample size limits. It is important to assess the content adequacy and construct validity of 
measures before drawing conclusions on the relevance of the findings from such measures (Hinkin, et al., 1997.) While previously validated measures were used in this investigation and the scales yielded acceptable reliability coefficients, these analyses represent only one step of many in the validation process. It would be prudent to retest and factor analyze these instruments using a larger sample of teams. A recent investigation along these lines has yielded similar results when looking at team processes among intact teams (Susskind, Rutherford \& Poorani, 1998), the observed consistency in results across studies is promising. However, additional investigations to further explore and clarify these issues are needed. This is particularly important given that this investigation included measures from a variety of sources, none of which were previously applied to groups in a foodservice laboratory setting.

\section{Conclusion}

Given the popularity of team based work and assignments in academia and educational curricula, this study highlights important components of the team interaction and how this interaction relates to performance outcomes. Educators should be aware that team composition and process have the potential to influence an individual's exposure to and potential for learning. Team-based assignments should only be applied in settings that will further benefit the students' learning and should not be applied for convenience to the instructional staff. It is recommended here that team membership be carefully considered and monitored rather than dealt with I randomly and that team-building components be included in team assignments and course work to maximize positive team process, TMX, and cohesion which directly influence team member satisfaction and performance. 


\section{Endnote}

1. The Campion et at., (1993) and Campion et aI., (1996) frameworks were adapted to this investigation. Several of the dimensions included in Campion's model did not match the nature of the team interaction examined in this investigation. In Campion's studies, the respondents were drawn from professional and clerical jobs, in which the structure and team interaction process varied among the teams investigated. This allowed for the measurement of the dimensions of job design, interdependence, and context in those settings. In the current investigation, the tasks and processes being performed by the teams were standardized and repeated among the teams, making the aforementioned dimensions less applicable here. Specifically, the dimensions of job design, interdependence, and context could not be well applied because the training, instructional support, team interaction, and range of tasks and duties were programmed within the course objectives, leaving room for little variance in the team members' responses. For that reason, the three dimensions (job design, inter dependence, and context) were not included. 


\section{References}

Bacon, D.R., Stewart, KA, \& Stewart Belle, S. (1998.) Exploring predictors of student team project performance. Journal of Marketing Education, 20, 63-71.

Bettenhausen, K.L. (1991.) Five years of group research: What have we learned and what needs to be addressed. Journal of Management, 17,345-381.

Campion, M.A., Medsker,G.J., \& Higgs, A.C. (1993.) Relations between work group characteristics and effectiveness: Implications for designing effective work groups. Personnel Psychology, 46, 823-850.

Campion, MA, Papper, EM., \& Medsker, G.J. (1996.) Relations between work team effectiveness: A replication and extension. Personnel Psychology, 49, 429-452.

Cohen, S.G., \& Bailey, D.E (1997.) What makes teams work: Group effectiveness from the shop floor to the executive suite. Journal of Management, 23, 239-290.

Danowski, J.A. (1980.) Group attitude belief uniformity and connectivity of organizational communication networks for production innovation, and maintenance content. Human Communication Research, 6, 299308.

Deeter-Schmelz, D.R., \& Ramsey, R. (1998.) Student team performance: A method for classroom assessment. Journal of Marketing Education, 20, 85-93.

Freeman, K.A. (1996.) Attitudes toward work in project groups as predictors of academic performance. SmallGroup Research, 27, 265-282.

Guzzo, RA, \&Shea, G.P. (1992.) Group performance and intergroup relations in organizations. In M.D. Dunnette \& L.M. Hough (Eds.,) Handbook of industrial and organizational psychology, Vol. 3 (2nd ed., 269-314.) Palo Alto, CA: Consulting Psychologists Press. 
Hackman, J.R. (1987.)The design of work teams. In J.W. Lorsch (Ed.) Handbook of organizational behavior (315-342). Englewood Cliffs, NJ: Prentice-Hall.

Hamilton, M.A., \& Hunter, J.E. (1995.) Pathe: A program in basic. Unpublished manuscript, University of Connecticut, Stoors.

Hinkin, T.R., Tracey, J.B., \&Enz, CA (1997.) Scale construction: Developing reliable and valid measurement instruments. Journal of Hospitality and Tourism Research, 21(1,) 100-120.

ligen, D.R., Major,DA, Hollenbeck, J.R., \& Sego, D.J. (1993.)Team research in the 1990s. In M.M. Chemers and Raymon (Eds.) Leadership and Organizational Journal of Hospitality \&Tourism Education Effectiveness (245-271). New York: Academic Press.

Jehn, KA (1997.)A qualitative analysis of conflict types and dimensions in organizational groups. Administrative Science Quarterly, 42, 530-557.

Magjuka, R.J., \& Baldwin, T.T. (1991.) Team-based employee involvement programs: Effects of design and administration. Personnel Psychology, 44, 793-812.

Pavitt, C., \&Curtis, E. (1990.) .small group discussion: A theoretical approach. Scottsdale, AZ: Gorsuch Scarisbrick Publishers.

Pritchard, R.D. (1992.) Organizational productivity. In M.D. Dunnette \& L.M. Hough (Eds.,) Handbook of industrial and organizational psychology. Vol. 3 (2nd ed., pp. 443-472.) Palo Alto, CA: Consulting Psychologists Press.

Pritchard, R.D., Jones, Roth, P.L., Stuebing, K.L., \& Ekeberg. S.E. (1988.) Effects of group feedback, goal setting, and incentives on organizational productivity. Journal of Applied Psychology, 73, 337-358. 
Sanders, W.G, \&Carpenter, MA (1998.) Internalization and firm governance: The roles of CEO compensation, top team composition, and board structure. Academy of Management Journal, 41, 158-178.

Seers, A. (1989.)Team-member exchange quality: A new construct for role making research. Organizational Behavior and Human Decision Processes, 43, 118-135.

Seers, A., Petty, M.M., \& Cashman, J.F. (1995.) Team-member exchange under team and traditional Management: A naturally occurring quasi-experiment. Group and Organization Management, 20, 183-8.

Shah, P.P. (1998.) Who are employees' social referents? Using a network perspective to determine referent others. Academy of Management Journal, 41, 249-268.

Shiflett, S. (1979.) Toward a general model of small group productivity. Psychological Bulletin, $86,67-79$.

Stokes, J.P. (1983.) Components of group cohesion: Inter member attraction, instrumental value, and risk taking. Small Group Behavior, 14,163-173.

Sundstrom, E, De Meuse, K.P., \& Futrell, D. (1990.) Work teams. American Psychologist, 45, $120-133$.

Susskind, A.M., Rutherford, D.G., \& Poorani, A.A. (1998.) Collaborative academic research among multi university project teams: An examination of communication network relationships, teamwork dimensions, and performance. Working paper, The School of Hotel Administration, Cornell University, Ithaca, NY.

Von Bertalanffy, L. (1968.) Systems Theory: Foundations. Developments. Applications. New York: Braziller. 